L17.1_0.02

\title{
Understanding coffee farmers: using games to explore future coffee agroforestry landscapes in the Western Ghats (India)
}

Garcia C. A. ${ }^{1}$ (claude.garcia@usys.ethz.ch), Vende J. ${ }^{2}$, Nanaya K. ${ }^{3}$, Nay M. ${ }^{4}$, Kalla J. ${ }^{5}$, Dray A. ${ }^{6}$, Delay M. ${ }^{6}$, Waeber P. ${ }^{6}$, Stoudmann N. ${ }^{6}$, Bose A. ${ }^{6}$, Le Page C. ${ }^{7}$, Raghuramulu Y. Bagchi R. ${ }^{9}$, Ghazoul J. ${ }^{10}$, Kushalappa C. ${ }^{3}$, Vaast P. ${ }^{11}$

${ }^{1}$ ForDev, CIRAD / ETHZ, Zurich, Zürich, Switzerland; ${ }^{2}$ AgroParisTech, Montpellier, France; ${ }^{3}$ Ponnampet College of Forestry, UHAS Shimoga, Shimoga, India; ${ }^{4}$ USYS, ETH Zurich, Zurich, Switzerland; ${ }^{5}$ French Institute of Pondicherry, Pondicherry, India; ${ }^{6}$ ForDev, ETH Zurich, Zurich, Switzerland; ${ }^{7} E S$, CIRAD, Montpellier, France; ${ }^{8}$ Central Coffee Board, Bangalore, India; ${ }^{2}$ Ecology and Evolutionary Biology, University of Connecticut, Stors, United States; ${ }^{10}$ Ecosystem Management, ETH Zurich, Zurich, Switzerland; ${ }^{11}$ Persyst, CIRAD, Montpellier, France

Deforestation and biodiversity loss in agroecosystems are the result of rational choices, not of a lack of awareness. Despite both scientific evidence and traditional knowledge that supports the value of diverse production systems for ecosystem services and resilience, a trend of intensification is apparent across tropical regions. These transitions happen in spite of policies that prohibit such transformations.

We present a participatory modelling study run (1) to understand the drivers of landscape transition and (2) to explore the livelihood and environmental impacts of tenure changes in the coffee agroforestry systems of Kodagu (India). The components of the system, actors and resources, and their interactions were defined with stakeholders, following the companion modelling (ComMod) approach. The underlying processes driving the system were validated through expert knowledge and scientific literature. The conceptual model was transformed into a Role Playing Game and validated by 8 workshops with 57 participants. Two scenarios were explored, a No Policy Change as baseline, and a Restitution of Rights where rights to cut the native trees are handed over to farmers. Our results suggest the landscape transition is likely to continue unabated unless there is a change to the current policy framework. However, the Restitution of tree Rights risks speeding up the process rather than reversing it, as slow variables such the differential growth rates between species kick in.

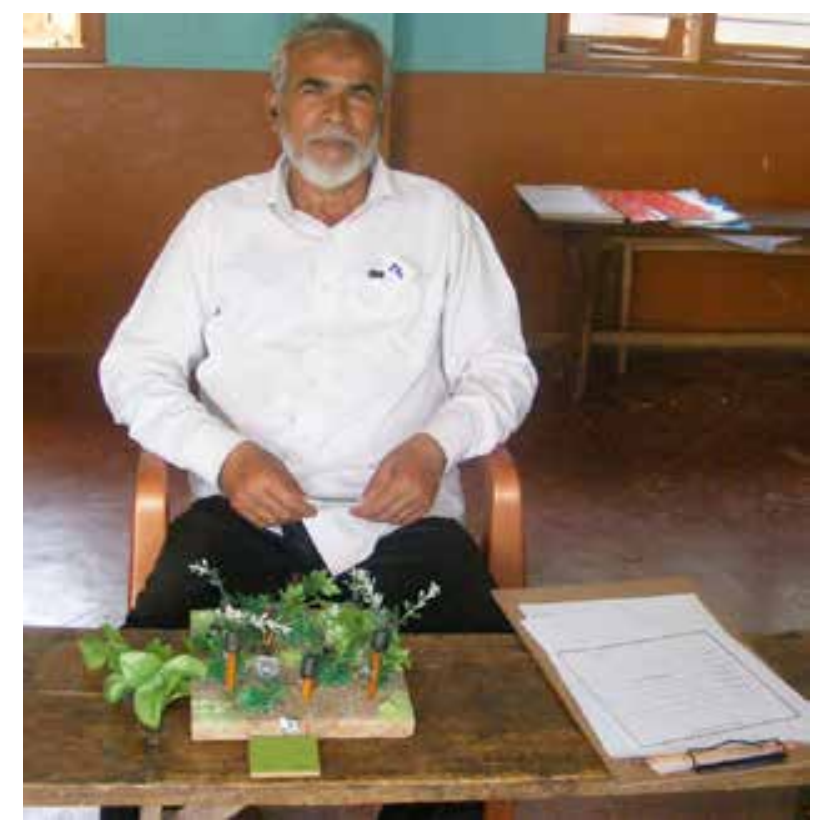

A coffee planter from Kodagu presents his coffee estate after one morning of play.

Keywords: Companion modelling, shade-grown coffee, tree rights, games.

References:

1. Garcia, C.A. et al., 2018. AgriXiv. https://doi.org/10.31220/osf.io/9374a 